\title{
Research on the Transformation and Development of Resource-oriented Cities Under the New Normal of Economy
}

\author{
TianTian $\mathrm{Gu}$ \\ School of Economics and Management \\ Zaozhuang University \\ Zaozhuang, China
}

\author{
$\mathrm{Na} \mathrm{Han*}$ \\ School of Economics and Management \\ Zaozhuang University \\ Zaozhuang, China \\ *Corresponding Author
}

\begin{abstract}
For a long time, the transformation development of resource-based cities have always been paid much attention. At present, the economic development of our country has entered The New Normal, how to promote the economic transformation and sustainable development of resource-based cities more scientifically and effectively, which has become an important subject needed to solve for the country for a long time to come. Resource-based cities should fully recognize the opportunities and challenges which they face under The New Normal, get a clear understanding of their own advantages and disadvantages, and choose a new path suitable for the transformation development of resource-based cities under The New Normal, so as to realize the sustainable development of the cities.
\end{abstract}

Keywords-The New Normal of economy; resource-based cities; economic transformation

\section{INTRODUCTION}

There are a lot of resource-based cities in our country, in the course of the economic development in our country, resource-based cities play a great role in promoting the development of national economy, providing basic raw materials and promoting the process of urbanization. However, through years of high-intensity development, resource-based cities are generally faced with a series of problems, such as the dwindling of resources reserves, the sharp deterioration of ecological environment, the difficulty of developing the alternative industries, the rising number of unemployed people, the gradual emergence of social contradictions and so forth, which lead to resource-based cities trapped in the dilemma of "mining exhausted and city decline", the sustainable development of the city is faced with severe challenges. Nowadays, the resources are increasingly scarce, how to promote the adjustment and optimization of economic industrial structure, accelerate the economic transformation of resource-based cities, and take the road of sustainable development as soon as possible has become a subject that needs to be considered and solved. Resource-based cities should fully recognize some new problems and new challenges they face under "The New Normal", and choose a new path suitable for the transformation and development of resource-based cities under The New Normal, so as to realize the sustainable development of the cities.

The New Normal is the new concept of ruling state and dealing with politics of the Party Central Committee with Xi Jinping as the General Secretary the CPC Central Committee. What The New normal economy shows in the economic development is a trend development status. Over the next period of time, the regular characteristics of economic development in our country mainly emphasize high efficiency, sustainability, low cost, and in terms of growth patterns, from the quantity expansion to the quality improvement; in the structural adjustment, the economic structure takes place the comprehensive, profound change, unceasingly optimizes the upgrades; in the power factor, by relying on the factor drive and the investment drive transformed into mainly depending on the innovation drive. In essence, after more than 30 years of rapid development, China's economy began to slow down and shift gears, saying goodbye to the previous unsustainable and unbalanced development model, which entered into a development model of high efficiency, sustainable and low cost, a comprehensive transformation was initiated. The essence of "The New Normal" is to enter a more stable stage of medium-high speed development through speeding up and shifting gears, structural adjustment as well as power conversion.

\section{THE NEW OPPORTUNITY FOR THE TRANSFORMATION}

\section{A. The Readjustment of Regional Economic Pattern Brings New Development Space}

China has more and more influence on the world economy, with the continuous improvement of the economic status of our country as well as the continuous deepening of international cooperation, the regional function orientation of resource-based cities in China will be further enhanced. Resource-based cities are involved in the cooperation of surrounding cities at the international level. Resource-based cities should firmly grasp the important period of national strategic development in the near future, actively apply for 
policies and funds for key industries and related infrastructure construction, speed up the construction of basic facilities, upgrade regional advantages, in addition, under The New Normal economy, resource-based cities rely on the complementary cooperation of resources and gradually develop to innovate and develop mutual-aid cooperation. More and more resource-based cities have the opportunity to participate in the division of labor of industrial chains and innovative products, and obtain certain benefits.

\section{B. The Reform of Domestic System and Mechanism Has Created New Vitality}

Deepening the market-oriented reform of state-owned enterprises and promoting the development of mixed ownership enterprises can give full play to the role of the market competition mechanism, improve the market competitiveness of enterprises, in addition, solve the problem of overcapacity and find the right direction for the development of resource-based cities. Under The New Normal, the government should give full play to the role of the market mechanism, fully mobilize the investment demand of enterprises and the consumption demand of the people, so as to alleviate the employment problem existing in the city, and promote the development of various industries at the same time.

\section{The Release of Domestic Demand Potential Under The New Normal Has Created a New Growth Motive}

With the increase of people's disposable income, the consumption of residents has gradually developed to the direction of individualization, diversification and high-end. The consumption demand of the residents has promoted the progress of technology, the renewal of business model, the abundance of products, at the same time, it also has greatly promoted the emergence and development of new industries, all of which provide an opportunity to cultivate new economic growth points for resource-based cities. Under The New Normal economy, our country has increased investment in urban infrastructure, while resource-based cities are inadequately invested in public consumption infrastructure, to improve investment in public consumption infrastructure construction, on the one hand, it can improve the speed of economic growth of resource-based cities; on the other hand, it can also improve the ecological environment quality of resource-based cities.

\section{CHALLENGES FACING THE TRANSFORMATION AND DEVELOPMENT}

With China's economic development entering The New Normal, the downward pressure of economic development is greater, what's more, the problems facing resource-based cities are more serious. The resource stock is reduced, the economic structure is single, lack of new industrial docking, and some industries have become excess capacity before they develop and mature. At the same time, resource-based cities also face a lot of environmental and social problems.

\section{A. The Traditional Mode of Relying on Resources to Develop the Economy Is Hard to Sustain}

Under The New Normal, the environmental carrying capacity of our country has reached or near the upper limit, and many resource-based cities will face the problem of resource depletion. Therefore, resource-based cities are in urgent need of the economic transformation such as a circular, green and low-carbon. At present, the plundering and extensive types exploitation of resources in some cities lead to the continuous deterioration of the ecological environment, such as land desertification, soil erosion, vegetation degradation, water pollution and other serious problems, resulting in huge economic losses, it also poses a great threat to the lives of local residents. The protection and management of ecological environment is a very important problem in the process of transformation of resource-based cities, which has a profound impact on the production and life of urban residents, what's more, has become a serious obstacle to the sustainable development of cities.

\section{B. A Strong Imprint of the Planned Economy and Lack of Market Mechanism}

Most of our country's resource-based cities were developed in the planned economy time, the stigma of planned economy is very heavy. The government has led the development of the economy, the enterprises are mainly state-owned enterprises, the development of private economy is seriously insufficient, and the development of small and medium-sized enterprises is lagging seriously. As a result of the squeeze of the state-owned economy, it is difficult for the non-state-owned economy to become active and grow up, therefore, the spontaneous effect of market mechanism cannot be given full play. Under this mechanism, the financial difficulties of the government are increased, the debt burden of the enterprises is heavy, and people's ideas and thoughts are also constrained, which has restrained the thought and consciousness of pioneering and innovating, and has become more difficult to adapt to the development of the socialist market economy, to a certain extent, this seriously hinders the economic transformation of resource-based cities.

\section{The Resource-based Economy Has a Adverse Effect on the Innovative Development of Resource-based Cities}

At present, the economic decline of resource-based cities in our country is due in large part to the lack of innovation. In resource-based cities, the dominance of resource-based industries has to a certain extent restrained the vitality of innovation. It makes resource-based cities lack of innovation power, slow pace of innovation, lack of competitiveness of innovation, lack power of sustainable development of cities.

\section{RESEARCH ON TRANSITION PATH OF RESOURCE- BASED CITIES}

\section{A. Optimize Investment Structure and Deepen Industrial Structure Adjustment}

Continuously optimize the investment structure, pay attention to the High-tech industry, new energy, materials 
and other fields of investment, actively invest in projects to promote economic development. We should increase investment in technological innovation, promote the development of high level industries, promote the transformation of high-tech achievements, promote the construction of modern industrial system with characteristics, and enhance competitiveness. Increase the investment of private capital, widen the investment field, guide the investment direction, encourage its investment to the basic industry, energy conservation and environmental protection industry. We will set up investment information network platform for Industrial policy, development planning and market access standards of all sectors of society to rationally adjust industrial structure and investment structure and promote social development. We should optimize the market competition mechanism, solve the problem of overcapacity, increase the construction of networked, digital and intelligent industries, and promote the optimization and upgrading of traditional industries. Unswervingly carry out technological innovation, product innovation, and actively develop new energy industries such as wind, solar, biomass and so on. The tourism resources of the city should be developed rationally, and eco-tourism and green tourism should be vigorously developed.

Industrial transformation and upgrading is the basic law of economic development. Resource-based cities should make full use of the local advantages of resources and location, extend the chain of resource industry and vigorously develop the alternative industries. Resource-based cities should ensure the development of resource-based industries in accordance with the actual situation of their own development, at the same time, they should increase efforts to actively develop the alternative industries with market competitiveness, and promote industrial development from the focus on quantity and speed changing to the focus on quality and efficiency.

\section{B. Intensifying Opening to the Outside World}

With the continuous development of our economy and the continuous deepening of opening to the outside world, resource-based cities should also enhance the depth and breadth of opening to the outside world, enhance their own international vision, and continue to participate in the foreign economic cooperation. Resource-based cities should seize the strategic opportunity of The Belt and Road, make full use of both domestic and foreign markets, and participate in domestic and foreign competition. On the one hand, rational and effective use of foreign capital invests in environmental protection industries, modern services and other high-tech new energy industries. On the other hand, enterprises are encouraged to go out and invest in overseas energy development and deep processing projects.

\section{Promoting the Urban and Rural Integration Process and Promoting New Urbanization}

In order to promote the transformation of the mode of economic development in our country under The New Normal, we need to increase the proportion of consumption, for resource-based cities, they should speed up the promotion of income of urban residents, especially rural residents, which is the premise and foundation to promote the rapid growth of consumption. Actively promoting urban and rural integration and promoting new type of urbanization construction can promote the free flow of resources and economic development.

Promoting new urbanization is a process that China must go through to push forward reform. We should promote development through innovation and development through demand, learn mature development concepts from foreign countries, and explore ways suitable for urban development in China. Balance urban and rural development. Various departments have advanced the integration of public services. We will guide funds to rural areas and support enterprises in rural areas through policy support, and promote the common progress and development of both rural and urban areas. Promote urban-rural integration by coordinating the allocation of funds, information and labor. We will build and develop industries with our own characteristics, promote agricultural science and technology, train modern farmers, and encourage scientific and technological innovation to promote agricultural modernization.

\section{Encouraging Independent Innovation}

The innovation of science and technology is the most critical foundation to realize the economic transformation smoothly in the resource-based city. On the one hand, technological innovation in resource-based industries can improve the efficiency of resource utilization and the quality of products, thus improving the cycle of resource utilization. On the other hand, it can also promote the formation of substitution industries and form a situation of common development of various industries, which can also improve the comprehensive competitiveness of resource-based cities to a certain extent. Enterprises should actively introduce domestic and foreign production factors, improve their production capacity and technology level, and use policy support to achieve industrial structure transformation and upgrading. The traditional investment mode is more extensive and does not meet the needs of current economic development. Therefore, it is necessary to optimize the efficiency of enterprise resource allocation and improve the efficiency of the use of corporate funds. At the same time, we should improve the innovation ability of talents, strengthen the innovation ability of employees and reserve talents through professional training and overseas training. We will improve the incentive policies for high-tech talents and establish a sound talent training mechanism.

In addition, resource-based cities should make use of their policy advantages to improve their ability and level of scientific and technological system reform. We should take ourselves as the main body of reform, coordinate political, industrial and scientific research activities, and establish an integrated center for scientific research, development and production. We will guide enterprises and universities to jointly develop products, and foreign enterprises to cooperate with local enterprises to bring into full play the synergistic effect of innovation and provide outstanding talents for economic development. We will make positive policy 
guidance, encourage enterprises to set up research centers, and give full play to their leading role in scientific and technological innovation. In order to improve the production technology level of enterprises, enterprises need to continuously introduce advanced technologies, master firstclass scientific and technological information through Internet big data, and actively invest in research and development funds. We will provide more and more hightech products and technologies to the Chinese market by focusing on scientific and technological innovation services.

\section{CONCLUSION}

The transformation of resource-based cities is comprehensive system engineering, involving many aspects, such as economic and social industrial policies, laws and so forth, it is a long process not overnight. However, in the process of transformation, the shortage of capital, the shortage of funds, the serious environmental damage, the single industrial development, the lack of development of follow-up industry and unclear development characteristics seriously restrict the sustainable development of resourcebased cities. The economic transformation has become the first difficult problem as well as the key point in the transformation of resource-based cities. Throughout the relevant cases at home and abroad on the transformation of resource-based cities, all of them are starting from the economic transformation, so the economic transformation of resource-based cities has played a supporting role in the transformation of the entire city. Exploring a suitable way of economic transformation will play a significant role in promoting the successful transformation of resource-based cities.

\section{REFERENCES}

[1] Innis. The Fur Trade in Canada [M].Toronto:University of Toronto Press, 1995.

[2] Lucas.Milltown.Railtown:Life in Canadian Communities of Single Industrys[M].Toronto: University of Toronto Pres, 1971.

[3] Robinson.Geographical Reviews [ J ].American Geographical Review, 1964.

[4] Hendrickson, C.T., et al. Environmental Life Cycle Assessment of Goods and Services: an Input-Output Approach[J]. Resources for the Future, 2005.

[5] Kucukvar, M.\& Tatari, O. Towards a triple bottom-line sustainability assessment of the U.S. construction industry[J]. Life Cycle Assess, 2013.

[6] Finnveden,G.,et al. Recent developments in life cycle assessment[J]. Environ.Manag,2009.

[7] Li Wenyan. Problems in industry development and urban planning[J]. Acta Geographica Sinica,1978.

[8] Ma Qingyu\&Sun Junjie.Study on rational distribution of mining towns[J]. Urban Planning, 1981. 